American Journal of Applied Sciences 7 (7): 1023-1025, 2010

ISSN 1546-9239

(C) 2010 Science Publications

\title{
A Good Solution for Household Based on Fast Waste Water Blockage Detection
}

\author{
${ }^{1}$ Mohammad Affendy Omardin, ${ }^{2}$ Ahmed N. Abdalla, \\ ${ }^{1}$ Mohd Helmi Suid and ${ }^{1}$ Noraziah Ahmad \\ ${ }^{1}$ Faculty of Civil Engineering and Earth Resources, \\ ${ }^{2}$ Faculty of Electrical and Electronic Engineering, \\ University of Malaysia Pahang, Malaysia
}

\begin{abstract}
Problem statement: The waste pipes from the wash basin are always flow in with several waste form kitchen preparation. Due to time consideration the pipe may comes through blockage and need blockage maintenance. Approach: This study presented an invention for early warning blockage detection for a kitchen waste water drain pipe. The waste water pipe some be connected through vertical pipe runs which are usually embedded in the wall. The Fast Waste Water Blockage Detection (FWABET) is to create early detection of a blocked waste water level at kitchen appliances means for quick action knowing fluid flow passing through detector and indicates sign and alarm. Results: User society and country will be benefited from FWABET such as restaurants, slaughters house, hotels, hospitals, building developers and plumbing contractors. It is the first invention in Malaysia and can be adapt as a part of building services requirements. Conclusion: It is concluded that by apply the FWABET's, it may reduce the costs and time of blockage waste water blockage drainage maintenance operations.
\end{abstract}

Key words: Waste, blockage, pipe, detector

\section{INTRODUCTION}

Internal waste pipes can easily become blocked over time with hair, grease, kitchen waste, etc. Putting off clearing them isn't a particularly good idea as over time not only will the water will cease to flow, but the smells from the drain and the rotting materials will become noticeable inside the property. If the pipe become so blocked that the water ceases to flow, then this can easily lead to damp forming on the internal walls of the property.

This project is especially adaptable to new environment in building which give the growth of building services environment which give as product benefits to develop a new fast waste water blockage pipe detection system, reduce maintenance cost of blockage pipe, new features of building fault detection, easy to implement and use.

System's function: Figure 1 shows the system block diagram including a filter, funnel, sensor housing, light sensor via waste indicator light, primary valve, as well as the other components shown in the drawings, wherein the filter comprises a vented plate that at the bottom of the elbow to allow the waste to travel downward under the force of gravity to the funnel where waste is directed to the clear tube connected to the bottom of the funnel (Ariffin and Talib, 2007).

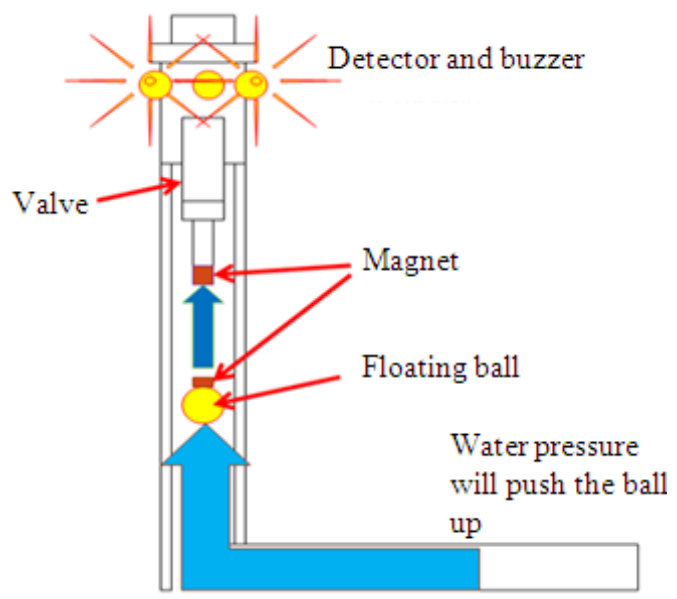

Fig. 1: System block diagram

Corresponding Author: Mohammad Affendy Omardin, Faculty of Civil Engineering and Earth Resources, University of Malaysia Pahang, Malaysia 
Am. J. Applied Sci., 7 (7): 1023-1025, 2010

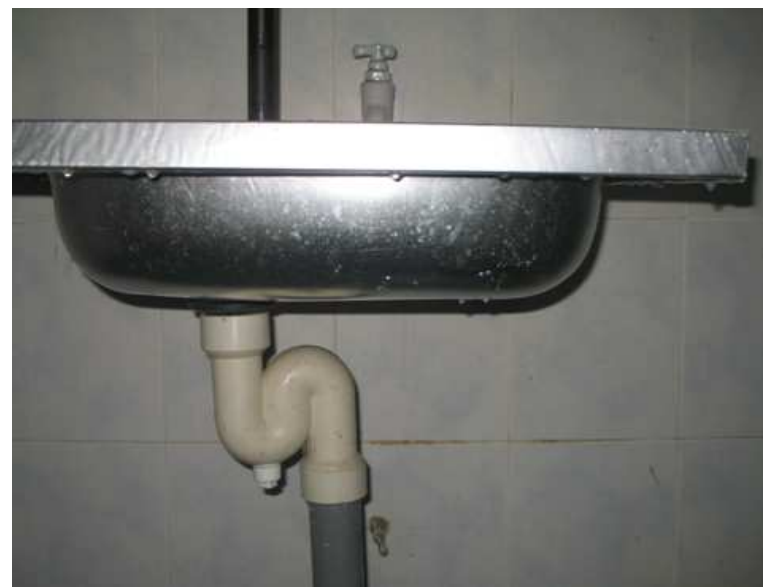

Fig. 2: Home application

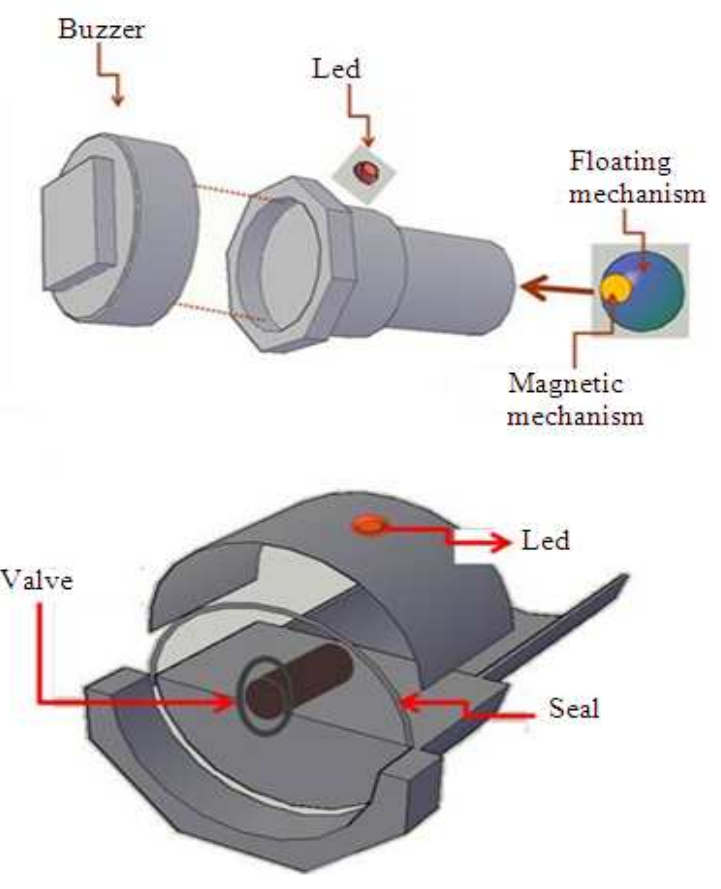

Fig. 3: The detection components

The sensor sends a signal to the waste indicator light when blocked causing the special buzzer to alarm as shown in Fig. 2. Figure 3 shows the kitchen having a drain outlet at the wash basin (Chudley and Greeno, 2005) as one application of our invention.

\section{MATERIALS AND METHODS}

FWABET system's potential market: Table 1 had shown the total price for all specific component and connection.
Table 1: FWABET's potential user

A potential customer user FWABET's

Taman Tunas Mahkota Kuantan

Taman Sri Periok Kelantan

Perumahan Seksyen 24 Shah Alam

Flat Seksyen 24 Shah Alam

Taman Perumahan Sri Hijau Taiping Perak

Total user Units

5

6

10

12

6

39 units

Table 2: Built-up detection system

Coast of built-up system per set of detector

Sensor detection (part A)

Led

Cost (RM)

Wiring

Valve

Floating mechanism

Stopper rubber

Total part A

Connection (part B)

Slender pipe

Elbow

Socket

Connector

Sealer

Filter

Siphon pipe

Tee joint

Total part B

Assemble for part A and B

Over all part A and B
10

5

10

5

31

2

2

8

3
6

6

7

6

39

15

85
System's development cost and comparisons: A key advantage of the detection devices is that the detector may helps in term of saving in cost of the cost of failure to detect blockage may higher environmental cleanup cost, higher building maintenance cost as shown in Table 2 and 3.

\section{In summary:}

Maintenance costs: RM 1855.00

Built-up detection system: $\mathrm{RM} 85.00 \times 10$ set $=\mathrm{RM}$ 850.00

Saving costs future maintenance: RM $1,005.00$ per maintenance

Finally it is clear the high maintenance cost to the building it necessary to apply this FWABET's.

\section{RESULTS AND DISCUSSION}

Cost benefit of FWABET's: The cost benefit for user FWABET'S as follows:

- FWABET's fast to install and assemble

- FWABET's reduces need for space during assemble 
Table 3: Cost of building waste water blockage maintenance system

Cost of building waste water blockage maintenance for a medium apartment (10 unit kitchen)

\section{Inspection (part A)}

Visual and typical inspection (consultation fees)

Replacement of siphon age pipe

Replacement of pipe (horizontal $40 \mathrm{~mm}$ pipe)

Replacement of pipe (vertical $30 \mathrm{~mm}$ pipe)

Sealants

Transportation

Workmanship

Replacement of flooring tiles

Replacement ceiling area

Overall cost

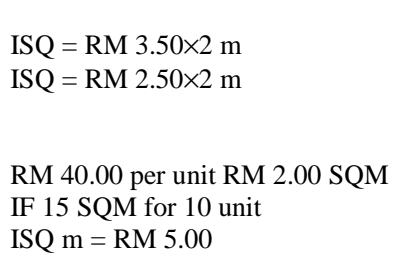

10 kitchen

10 kitchen

10 kitchen

(0)

10 kitchen

15 SQM per unit

Cost (RM)

- Lightweight items

- $\quad$ Easy to install to drain pipe outlet

- Less maintenance in future

- Less of operative

\section{CONCLUSION}

The comfort and healthy in building design need to utilize collaborative with other professionals in the design stage, as well as architects, interior architects and building services engineer. Therefore by apply the FWABET's, it may reduce the costs and time of blockage waste water blockage drainage maintenance operations. This product may put into added value in term of value propositions (Dallas, 2005). In addition the FWABET's in term of customer value proposition and potential customers may apply such as:

- Factories

- Ministry of Health

- Ministry of Housing and Development

- Construction Industry, Development Board Malaysia (CIDB)

\section{REFERENCES}

Ariffin, J. and S.A. Talib, 2007. Problem Solving in Fluid Mechanics. University Publication Centre (UPENA), UiTM, pp: 32-36.

Chudley, R. and R. Greeno, 2005. Construction Technologies. 3rd Edn., Pearson Longman, ISBN: 10: 0131286420, pp: 648.

Dallas, M.F., 2005. Concepts, Standards and Qualifications. CIOB Blackwell Publishing, pp: 117-124. 